\title{
Using Cerebrospinal Fluid Biomarker Testing to Target Treatment to Patients with Mild Cognitive Impairment: A Cost-Effectiveness Analysis
}

\author{
Tzeyu L. Michaud ${ }^{1,2}$ (D) Robert L. Kane ${ }^{3} \cdot$ J. Riley McCarten ${ }^{4,5} \cdot$ Joseph E. Gaugler $^{6}$ \\ John A. Nyman ${ }^{3}$ Karen M. Kuntz ${ }^{3}$
}

Published online: 29 August 2017

(C) The Author(s) 2017. This article is an open access publication

\begin{abstract}
Objective Cerebrospinal fluid (CSF) biomarkers are shown to facilitate a risk identification of patients with mild cognitive impairment (MCI) into different risk levels of progression to Alzheimer's disease (AD). Knowing a patient's risk level provides an opportunity for earlier interventions, which could result in potential greater benefits. We assessed the cost effectiveness of the use of CSF biomarkers in MCI patients where the treatment decision was based on patients' risk level.
\end{abstract}

Electronic supplementary material The online version of this article (doi:10.1007/s41669-017-0054-z) contains supplementary material, which is available to authorized users.

Tzeyu L. Michaud

tzeyu.michaud@unmc.edu

1 Center for Reducing Health Disparities, College of Public Health, University of Nebraska Medical Center, Omaha, NE, USA

2 Department of Health Promotion, Social and Behavioral Health, College of Public Health, University of Nebraska Medical Center, Omaha, NE, USA

3 Division of Health Policy and Management, School of Public Health, University of Minnesota, Minneapolis, MN, USA

4 Geriatric Research, Education and Clinical Center, Minneapolis Veterans Affairs Medical Center, Minneapolis, MN, USA

5 Department of Neurology and Psychiatry, University of Minnesota Medical School, Minneapolis, MN, USA

6 School of Nursing and Center on Aging, University of Minnesota, Minneapolis, MN, USA
Methods We developed a state-transition model to project lifetime quality-adjusted life-years (QALYs) and costs for a cohort of 65-year-old MCI patients from a US societal perspective. We compared four test-and-treat strategies where the decision to treat was based on a patient's risk level (low, intermediate, high) of progressing to AD with two strategies without testing, one where no patients were treated during the MCI phase and in the other all patients were treated. We performed deterministic and probabilistic sensitivity analyses to evaluate parameter uncertainty.

Results Testing and treating low-risk MCI patients was the most cost-effective strategy with an incremental cost-effectiveness ratio (ICER) of US $\$ 37,700$ per QALY. Our results were most sensitive to the level of treatment effectiveness for patients with mild $\mathrm{AD}$ and for $\mathrm{MCI}$ patients. Moreover, the ICERs for this strategy at the 2.5th and 97.5th percentiles were US $\$ 18,900$ and US $\$ 50,100$ per QALY, respectively.

Conclusion Based on the best available evidence regarding the treatment effectiveness for MCI, this study suggests the potential value of performing CSF biomarker testing for early targeted treatments among MCI patients with a narrow range for the ICER.

\section{Key Points for Decision Makers}

Treating MCI patients at low risk generated greater benefits, although it may be counterintuitive.

With a high degree of uncertainty, the decision of whether to treatment MCI patients or not based on their risk levels may benefit from gathering more information on the treatment effectiveness for MCI. 


\section{Introduction}

Alzheimer's disease (AD) is a devastating neurodegenerative disease that impairs memory, thought, and behavior; reduces quality of life; and decreases survival. As more people live long enough to become at-risk $[1,2]$, identifying patients early in the disease continuum for greater benefits from the potential interventions may alleviate some of the burden on patients, caregivers, and society $[3,4]$.

Prior to AD diagnosis, most patients progress through a prodromal stage called mild cognitive impairment (MCI) [5], which is a stage characterized by early memory loss but with relatively well-preserved activities of daily living. On average, MCI patients face a $10-15 \%$ risk of progression to $\mathrm{AD}$ each year [5-10]. Identifying patients at risk for progression to $\mathrm{AD}$ at an earlier stage provides an opportunity to make decisions about disease management plans and financial arrangements while cognitive function is still capable $[11,12]$, and to access interventions with diseasemodifying effects if they were to become available $[13,14]$.

Cerebrospinal fluid (CSF), consisting of a concentration of $A \beta_{1-42}$ (a biomarker of amyloid $\beta$ deposition in the brain), total tau, and phosphorylated tau proteins $[15,16]$, are shown to facilitate the identification of MCI patients who are at different risk levels of progression to $\mathrm{AD}$ $[13,17-19]$ and are included in the currently proposed diagnostic criteria for AD [13] and MCI [20]. Moreover, they are also considered the most preferred biomarkers for studying disease progression due to their unique clinical features and low incidences of complications [21, 22]. Accordingly, several multidisciplinary working groups have either recommended using CSF biomarkers in the diagnostic workup of MCI patients [23] or proposed the utilization of CSF biomarkers in informing the likelihood of the progression to $\mathrm{AD}$ among MCI patients [4, 24].

There is currently no cure for AD. With a hypothetical disease-modifying therapy (DMT), however, data from several simulation models supported the benefits of early identification at the prodromal or predementia stage using various diagnostic tools such as florbetaben positron emission tomography [25], brain magnetic resonance imaging [26], apolipoprotein $\epsilon 4$ genetic test [27], or CSF biomarkers $[28,29]$. In addition, some models compared the strategy of a DMT versus the strategy of no DMT in patients with MCI (the decision to treat or not was not based on the testing results) [30, 31]; others compared different diagnostic strategies with these novel testing techniques as an add-on to standard diagnostic procedures $[25,26,28]$.

The potential value of these tools to facilitate the detection of $\mathrm{AD}$ at an early phase is only considered speculative [14] due to the scant evidence pertaining to the effectiveness of existing treatments for MCI patients. Yet, results of a randomized clinical trial (RCT) [32] and metaanalysis studies [33-37] showed the potential benefits of cholinesterase inhibitors (ChEIs; e.g., donepezil, galantamine, and rivastigmine) to delay the progression from MCI to AD. Additionally, it is suggested by the recent revision of cost-effectiveness analysis (CEA) recommendations [38] that if a decision must be made (in our case whether or not to intervene for MCI patients based on their CSF biomarker test results), it should be made based on the data availability. Given the clinical utility of CSF biomarkers and the best available data on treatment effectiveness, therefore, the objective of our study was to determine the potential value of the use of CSF biomarker testing in MCI patients by comparing various test-and-treat strategies with strategies without test information. Here, CSF biomarkers were used as a risk-stratification tool to categorize patients into different risk levels of progression to AD (instead of a diagnostic tool to dichotomize patients into positive or negative testing results), and the decision to treat was based on a patient's risk level.

\section{Methods}

We developed a state-transition model to estimate the costs, quality-adjusted life-years (QALYs), and cost effectiveness of performing one-time CSF biomarker testing for a cohort of 65-year-old MCI patients and then treating some of these patients with ChEIs based on their biomarker test results. We used evidence from a primary data analysis [19] and the published literature to derive relevant parameters. Costs and health outcomes were discounted $3 \%$ annually per the US recommendation [39], and the model cycle length was 1 year. We adopted a US societal perspective and a lifetime horizon.

\subsection{Model Structure}

Figure 1 illustrates the model structure. MCI patients who undergo biomarker testing are assigned a high-, intermediate-, or low-risk score that determines their risk of progressing to $\mathrm{AD}$ [19]. On the basis of this score, a subset of patients would be treated with ChEI therapy in the MCI stage. Providing treatment in this phase introduces a cost and imposes a risk of experiencing side effects but also might reduce a patient's risk of developing $\mathrm{AD}$. If MCI patients progress to $\mathrm{AD}$, whether treated or not, they progress through a series of health states defined by $\mathrm{AD}$ severity (mild, moderate, or severe) and residential settings (community or nursing home). Each year, patients are 


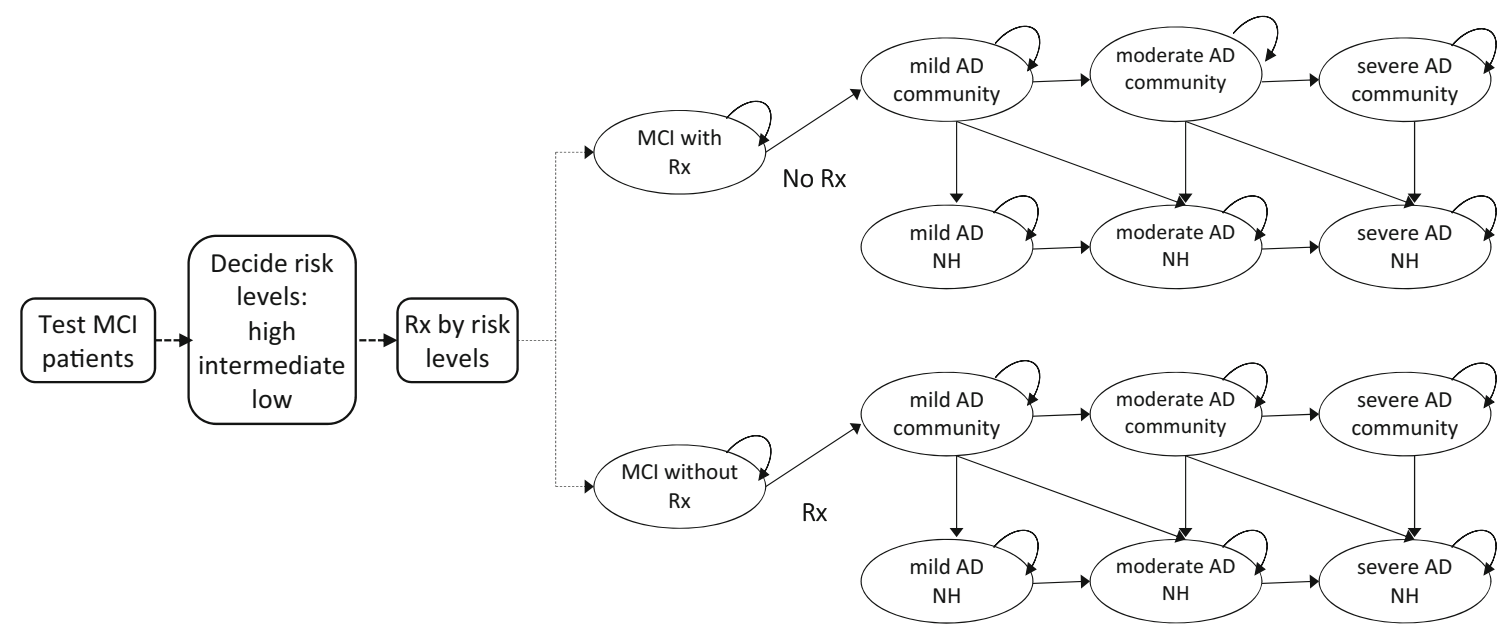

Fig. 1 Schematic diagram of CSF biomarker testing and subsequent treatment for patients with MCI. AD Alzheimer's disease, CSF cerebrospinal fluid, $M C I$ mild cognitive impairment, $N H$ nursing home, $R x$ treatment

allowed to transition to another health state (progress in severity or transition to nursing home), remain in the same health state, or die. Once AD patients enter a nursing home we assumed that they would remain in the institution until death [40], given that most patients entering the nursing home have severe AD.

\subsection{Treatment Strategies}

Because MCI patients could be categorized into one of three risk levels of progression to AD based on their CSF biomarker testing results (a positive and ordinal relationship), we evaluated six test-and-treat strategies as follows:

1. No testing and no MCI treatment Treat only when MCI patients convert to $\mathrm{AD}$ and stop treatment when they progress to the severe stage.

2. Test and treat high risk Test MCI patients and only treat those with a high-risk result until AD conversion; no treatment for low- and intermediate-risk patients until they convert to $\mathrm{AD}$ and stop treatment when they progress to the severe stage.

3. Test and treat high or intermediate risk Test MCI patients and treat those with a high- or intermediaterisk result until $\mathrm{AD}$ conversion; no treatment for lowrisk patients until they convert to $\mathrm{AD}$ and stop treatment when they progress to the severe stage.

4. Test and treat low risk Test MCI patients and treat those with a low-risk result until $\mathrm{AD}$ conversion; no treatment for high- and intermediate-risk patients until they convert to $\mathrm{AD}$ and stop treatment when they progress to the severe stage.

5. Test and treat low or intermediate risk Test MCI patients and treat those with a low- or intermediate-risk result until $\mathrm{AD}$ conversion; no treatment for high-risk patients until they convert to $\mathrm{AD}$ and stop treatment when they progress to the severe stage.

6. No testing and treat all MCI patients Treat all MCI patients and stop treatment when patients convert to $\mathrm{AD}$.

Because evidence on the treatment effectiveness for MCI patients is indefinite, we assumed that if MCI patients received treatment, they would not be eligible for $\mathrm{ChEI}$ treatment if they converted to AD based on clinical expert opinion. We tested this assumption in the sensitivity analysis.

\subsection{Model Parameters}

Table 1 summarizes the parameter estimates and their $95 \%$ confidence intervals (CIs) if available. Otherwise, we used $50 \%$ higher or lower than the mean as the upper bound and lower bound for the parameter estimate [41].

\subsubsection{Disease Progression}

In previous work [19], we estimated annual transition probabilities from MCI to $\mathrm{AD}$ for each risk group (high, intermediate, and low) defined by CSF biomarker levels using 6-year follow-up data from the Alzheimer's disease Neuroimaging Initiative with 195 MCI patients. In brief, time-dependent receiver operator characteristic analysis was used to choose the best combination of CSF biomarkers on the longitudinal predictive ability for the progression of $\mathrm{AD}$ for MCI patients. Baseline CSF biomarker levels were summarized into a multi-biomarker score by multiplying the biomarker level with each of their own coefficients $\left([-0.006] \times \mathrm{A} \beta_{1-42}+0.012 \times \mathrm{P}\right.$ $\operatorname{tau}_{181 \mathrm{p}}$ ) [19], derived from the fitted Cox proportional 
Table 1 Parameter inputs for the state-transition model

\begin{tabular}{|c|c|c|c|c|}
\hline Parameter & Mean & $95 \% \mathrm{CI}$ & Distribution & Source \\
\hline \multicolumn{4}{|c|}{ Annual probability of progression from MCI to AD by CSF biomarker score ${ }^{\mathrm{a}}$} & \multirow[t]{4}{*}{ [19] } \\
\hline Low-risk group & 0.064 & $0.01-0.16$ & Beta $(2.46,35.93)$ & \\
\hline Intermediate-risk group & 0.108 & $0.03-0.22$ & Beta $(4.05,33.48)$ & \\
\hline High-risk group & 0.244 & $0.17-0.33$ & Beta $(27.89,86.40)$ & \\
\hline \multicolumn{4}{|l|}{ Prevalence of MCI patients by risk levels } & \multirow[t]{4}{*}{ [19] } \\
\hline Low-risk group & 0.6 & & & \\
\hline Intermediate-risk group & 0.2 & & & \\
\hline High-risk group & 0.2 & & & \\
\hline \multicolumn{4}{|l|}{ Annual transition probability } & \multirow[t]{9}{*}[40,79]{} \\
\hline \multicolumn{4}{|l|}{ Stage to stage $(\mathrm{AD})$} & \\
\hline Mild to moderate & 0.167 & $0.156-0.178$ & Beta $(690.43,3443.86)$ & \\
\hline Mild to severe & 0.014 & $0.010-0.018$ & Beta $(59.63,4199.86)$ & \\
\hline Moderate to severe & 0.299 & $0.286-0.312$ & Beta $(1355.02,3176.83)$ & \\
\hline \multicolumn{4}{|l|}{ Community to nursing home } & \\
\hline Mild AD & 0.012 & $0-0.028$ & Beta $(2.27,186.70)$ & \\
\hline Moderate AD & 0.034 & $0-0.069$ & Beta $(3.57,101.46)$ & \\
\hline Severe AD & 0.066 & $0.005-0.128$ & Beta $(3.74,52.91)$ & \\
\hline Excess mortality due to $\mathrm{AD}$ (additive effect) ${ }^{\mathrm{b}}$ & 0.11 & $0.055-0.165$ & & {$[53,54]$} \\
\hline \multicolumn{5}{|l|}{ Treatment effectiveness (RR) } \\
\hline MCI patients & 0.84 & $0.70-1.02$ & Lognormal $(-0.17,0.096)$ & {$[36]$} \\
\hline \multicolumn{5}{|l|}{ AD patients } \\
\hline Mild to moderate & 0.58 & $0.35-0.76$ & Lognormal $(-0.55,0.198)$ & Estimated by authors \\
\hline Moderate to severe & 0.95 & $0.64-1.41$ & Lognormal $(-0.05,0.114)$ & {$[42]$} \\
\hline \multicolumn{5}{|l|}{ Treatment harm } \\
\hline Annual prob. of AE (control) & 0.23 & $0.2-0.26$ & Beta $(173.78,581.77)$ & [43] \\
\hline AEs in MCI (RR) & 1.09 & $1.02-1.16$ & Lognormal $(0.086,0.033)$ & {$[36]$} \\
\hline AEs in AD (RR) & 2.09 & $1.81-2.40$ & Lognormal $(0.736,0.073)$ & [44] \\
\hline Withdrawal due to $\mathrm{AE}^{\mathrm{c}}$ & 0.18 & $0.13-0.22$ & Beta $(41.67,181.76)$ & {$[44]$} \\
\hline Withdrawal due to non-AE in MCI & 0.046 & $0.035-0.058$ & Beta $(52.94,1201.7)$ & Assumed \\
\hline Withdrawal due to non-AE in $\mathrm{AD}$ & 0.11 & $0.10-0.12$ & Beta $(190.03,1543.9)$ & Assumed \\
\hline \multicolumn{5}{|l|}{ Health utility } \\
\hline MCI & 0.73 & $0.58-0.88$ & Beta $(23.86,8.82)$ & {$[27,80]$} \\
\hline $\mathrm{AD}$ & & & & [49] \\
\hline \multicolumn{5}{|l|}{ Mild } \\
\hline Community & 0.68 & $0.54-0.82$ & Beta $(28.34,13.34)$ & \\
\hline Nursing home & 0.71 & $0.57-0.85$ & Beta $(27.97,11.42)$ & \\
\hline \multicolumn{5}{|l|}{ Moderate } \\
\hline Community & 0.54 & $0.43-0.65$ & Beta $(42.08,35.85)$ & \\
\hline Nursing home & 0.48 & $0.37-0.59$ & Beta $(37.59,40.72)$ & \\
\hline \multicolumn{5}{|l|}{ Severe } \\
\hline Community & 0.37 & $0.29-0.45$ & Beta $(67.3,114.6)$ & \\
\hline Nursing home & 0.31 & $0.24-0.38$ & Beta $(51.72,115.11)$ & \\
\hline $\mathrm{AE}^{\mathrm{d}}$ & 0.95 & $0.916-0.976$ & Beta $(190,10)$ & [29] \\
\hline Lumbar puncture $^{\mathrm{d}}$ & 0.01 & $0.009-0.012$ & Beta $(9800,99)$ & Assumed, [52] \\
\hline \multicolumn{5}{|l|}{ Cost (US\$, per person-year) } \\
\hline MCI & 7467 & $3733-11,200$ & Gamma $(15.36,0.0021)$ & {$[56]$} \\
\hline Formal & & & & [55] \\
\hline
\end{tabular}


Table 1 continued

\begin{tabular}{|c|c|c|c|c|}
\hline Parameter & Mean & $95 \% \mathrm{CI}$ & Distribution & Source \\
\hline Community & 9380 & $4690-14,070$ & Gamma $(15.37,0.0017)$ & \\
\hline Nursing home & 50,865 & $25,432-76,297$ & Gamma $(15.37,3.06)$ & \\
\hline \multicolumn{5}{|l|}{ Moderate AD } \\
\hline Community & 13,859 & $6929-20,788$ & Gamma $(15.37,0.0011)$ & \\
\hline Nursing home & 55,362 & $27,681-83,043$ & Gamma $(15.37,2.81)$ & \\
\hline \multicolumn{5}{|l|}{ Severe AD } \\
\hline Community & 20,889 & $10,445-31,334$ & Gamma $(15.37,7.46)$ & \\
\hline Nursing home & 59,327 & $29,664-88,991$ & Gamma $(15.37,2.63)$ & \\
\hline Informal & & & & {$[55]$} \\
\hline \multicolumn{5}{|l|}{ Mild AD } \\
\hline Community & 11,876 & $5938-17,815$ & Gamma $(15.37,0.0013)$ & \\
\hline Nursing home & 1267 & $633-1900$ & Gamma $(15.33,0.0127)$ & \\
\hline \multicolumn{5}{|l|}{ Moderate AD } \\
\hline Community & 20,559 & $10,279-30,838$ & Gamma $(15.37,7.58)$ & \\
\hline Nursing home & 973 & $486-1459$ & Gamma $(15.35,0.016)$ & \\
\hline \multicolumn{5}{|l|}{ Severe AD } \\
\hline Community & 20,724 & $10,362-31,086$ & Gamma $(15.37,7.52)$ & \\
\hline Nursing home & 1028 & $514-1542$ & Gamma $(15.33,0.0151)$ & \\
\hline Drug (donepezil) & 2884 & $1442-4325$ & Gamma $(15.35,0.0054))$ & AWP, [57] \\
\hline Office visit due to treatment (per time) & 83 & $42-125$ & Gamma $(14.88,0.1837)$ & [49] \\
\hline CSF biomarker testing (per person) & 324 & $162-487$ & Gamma $(15.50,0.0492)$ & {$[25]$} \\
\hline
\end{tabular}

$A D$ Alzheimer's disease, $A E$ adverse event, $A W P$ average wholesale price, $C I$ confidence interval, $C S F$ cerebrospinal fluid, $M C I$ mild cognitive impairment, $R R$ relative risk

a CSF biomarker scores were calculated by the equation: $(-0.006) \times \mathrm{A} \beta_{1-42}+0.012 \times \mathrm{P}-\mathrm{tau}_{181 \mathrm{p}}$ [19]. The three risk groups were defined by the quintiles of the scores: high risk (the 3rd, 4th, and 5th quintiles), intermediate risk (the 2nd quintile), and low risk (the 1st quintile). Annual transition probability of each risk group was converted from the 6-year cumulative probability estimated by the Kaplan-Meier survival functions

b Applied only to patients with severe $\mathrm{AD}$ and half of this to patients with moderate $\mathrm{AD}$. We assumed MCI patients and patients with mild $\mathrm{AD}$ have the similar background all-cause mortality rate in terms of age

c Annual probability derived from 6-month data by the exponential function $(0.18=1-\exp [-0.0964 \times 2])$

d Incorporated as disutility due to the treatment or lumbar puncture

hazard model for the best combination of CSF biomarker. The three risk groups were defined by the quintiles of the multi-biomarker score: high risk (the 3rd, 4th, and 5th quintiles), intermediate risk (the 2nd quintile), and low risk (the 1st quintile). We calculated the cumulative probability of progression to AD for each risk group using the KaplanMeier survival functions. For each risk group, we converted the 6-year cumulative probability into an annual probability of progression to $\mathrm{AD}$ (conditional on still being in the MCI state) and used this annual probability in our decision model, assuming a constant probability over the 6 years.

For transitions among AD stages, we used probabilities estimated by Spackman et al., who analyzed data from the Uniform Data Set of the National Alzheimer Coordinating Center [40]. They reported estimated probabilities of stageto-stage transitions and probabilities of community-tonursing-home transitions conditional on AD stage. Based on the rule of conditional probability, we calculated the combined stage and nursing home transition probabilities (e.g., moving from mild $\mathrm{AD}$ community setting to mild $\mathrm{AD}$ nursing home) by multiplying these two transition probabilities together. We assumed that the risk of transitioning from community to nursing home conditional on $\mathrm{AD}$ stage is as reported and does not change for those persons who progress to different $\mathrm{AD}$ stages within the year.

\subsubsection{Treatment Effectiveness}

A recent Cochrane review [36] reported the relative risk (RR) of progression to dementia as $0.84 \quad(95 \%$ CI 0.70-1.02) over 3 years (although effects for year 1 and year 3 were borderline significant) in MCI patients treated with a ChEI. Namely, it represents a $16 \%$ reduction of the annual progression risk from $\mathrm{MCI}$ to $\mathrm{AD}$. In our base-case analysis we assumed that the effect persisted for only the first 3 years of treatment based on the synthesized results of the review. 
The effectiveness parameter of ChEI treatment applied to patients with moderate $\mathrm{AD}$ was derived directly from an RCT [42], but we computed the RR for patients with mild $\mathrm{AD}$ using the data provided in the same RCT due to lack of directly applicable information. The RRs were $0.58(95 \%$ CI $0.35-0.76)$ and 0.95 (95\% CI 0.64-1.41) for patients with mild $\mathrm{AD}$ and moderate $\mathrm{AD}$, respectively. In other words, mild AD patients treated with ChEIs experience a $42 \%$ reduction in the annual risk of transitioning to either moderate or severe $\mathrm{AD}$, whereas the reduction was $5 \%$ for moderate $\mathrm{AD}$ patients receiving treatment transitioning to severe AD.

\subsubsection{Adverse Events (AEs) Associated with Treatment}

We used the result from a systematic review [43] for the annual risk of AEs (0.23) in the placebo arm of donepezil trials for MCI patients as the baseline risk for both MCI and $\mathrm{AD}$ patients receiving no treatment in our model. The reported RR of overall AEs between the treatment and the control groups for MCI patients was 1.09 (95\% CI 1.02-1.16) [36]. For AD patients, we converted the reported odds ratio (OR) [44] to RR using methods from the Cochrane Handbook [45]. The converted RR was 2.09 (95\% CI 1.81-2.40).

Despite a low frequency of complications for lumbar puncture [46], such as post-lumbar puncture headache, especially in the elderly population [47, 48], we took into account AEs due to CSF biomarker testing in the present study.

\subsubsection{Withdrawal of Cholinesterase Inhibitor (ChEI) Treatment}

We assumed that if patients discontinued treatment, they would experience the same risks of transitioning to the next health state as untreated patients. We did not assume any residual effects of treatment. In addition, MCI patients who discontinued the treatment would not be subsequently treated, even though they converted to AD. A systematic review [44] of 10 RCTs examining the efficacy of ChEIs among AD patients showed that more patients discontinued therapy due to AEs in the treatment group (18\%) than in the placebo group (8\%) within a study period of 6 months for all but two studies. We derived an annual withdrawal probability of $18 \%$ (95\% CI 13-22\%) conditional on experiencing an AE. Due to data availability, we applied this annual probability derived from $\mathrm{AD}$ patients to MCI patients as MCI is considered as the prodromal stage of AD [5] and the medication considered in the present study is one of the ChEIs. We also calculated the annual probability of withdrawal from treatment due to other reasons (excluding AEs) as $4.6 \%(95 \%$ CI $3.5-5.8 \%)$ and $11 \%(95 \%$
CI $10-12 \%$ ) for MCI and AD patients receiving treatment, respectively.

\subsubsection{Health Utilities}

We assigned health-related quality-of-life weights to disease severity and residential settings based on analyses by Neumann et al. [49, 50], because it was one of the few studies that estimated health utilities for joint states defined by disease severity and residential settings. In the study, they acquired quality-of-life weights, stratified by disease stage and setting, using the Health Utilities Index Mark II (HUI:2), which was administered in a companion, cross-sectional study of 528 caregivers of AD patients in the US [50]. Caregivers were asked to answer the questionnaire as the proxy respondents. Later, the responses to the questionnaire were converted into preference weights using the HUI:2 multi-attribute utility function [51]. Due to the absence of a range of quality-of-life weights by residential settings reported in their study, we applied the estimates of the standard error for $\mathrm{AD}$ patients dwelling in the community to $\mathrm{AD}$ patients in the nursing home. In addition, we also accounted for the quality-of-life decrement resulting from AEs due to the treatment, which was specified at 0.05 [29] as long as the treatment was provided. This disutility was accounted for by multiplying the assigned utility for each relevant state (e.g., MCI, mild $\mathrm{AD}$, or moderate $\mathrm{AD}$ ) by 0.95 . The one-time disutility of 0.01 following the lumbar puncture (for CSF biomarker testing) was derived from the literature where the assumption was made [52].

\subsubsection{Excess Mortality}

The annual excess mortality rate among patients with severe $\mathrm{AD}$ was estimated at 0.11 by the additive model $[53,54]$. We assumed that patients with moderate AD would experience half of the excess rate (i.e., we added 0.055 to the background death rates for patients in the moderate $\mathrm{AD}$ stage) and tested this assumption with a multiplier (range 10-90\%) of excess mortality in the sensitivity analysis. We assumed that this additive effect is the same regardless of the patients' age or gender [53]. We assumed that the mortality rate for patients in the MCI and mild $\mathrm{AD}$ stage is equal to the background all-cause mortality rate.

\subsubsection{Costs}

We took a modified US societal perspective to include medical costs, and time costs of informal caregiving in the CEAs. In addition, the healthcare sector perspective (informal costs excluded) was also considered. 
Formal and informal care We used the cost estimates reported by Leon et al. [55] for patients with AD based on severity and residential (community or nursing home) setting. These costs include both formal (paid health services) and informal care (defined as paid and unpaid services) for AD patients, where informal costs were estimated by replacement wages. We converted monthly costs to annual costs to assign to the relevant health states in our model. Because the variance $(95 \%$ CI) of costs was not reported in the study, we assumed that the cost estimate for each health state in the model was $50 \%$ lower or higher from the mean of point estimates for the lower bound and the upper bound, respectively.

For the costs incurred in the MCI stage, we used data from Leibson et al. [56] to inform formal healthcare costs, including medical costs, pharmaceuticals, and informal healthcare costs (home care, assisted living, and transport) for MCI patients.

We did not account for the non-healthcare direct costs resulting from the loss of productivity of patients due to disease progression because we targeted the 65-year-old population. The CEA results presented included both formal and informal costs unless specified.

Medication We based the unit costs for AD medications on the average wholesale price reported in the Red Book [57]. The daily costs for these drugs were calculated based on their recommended dose and usage from the licensed labels. Because the drug is currently off-patent, we derived the medication cost at the available market price (US\$7.79) per day (the cost for donepezil $5 \mathrm{mg}$ is the same as $10 \mathrm{mg}$ ) and the largest pack size. We estimated the annual drug costs as $365.25 \times$ US\$7.79 $=$ US\$2845. For the follow-up cost due to the treatment, we continued the assumption made by a previous study [49] that donepezil would induce two and one extra office visits every year along with the treatment effect duration for MCI and AD patients, respectively. One office visit was associated with US\$82 as estimated by the previous study [49].

CSF biomarker testing The cost of CSF biomarker analysis, a one-time cost per patient, was estimated using the cost data from Centers for Medicare and Medicaid Services hospital outpatient fee schedule [25].

Because the ChEI treatment-induced AEs are generally mild or moderate $[36,58]$, we did not consider the costs of treating AEs but the disutility associated with those AEs. All cost estimates were inflated to 2016 US dollars using the Consumer Price Index [59] if needed.

\subsection{Analyses}

\subsubsection{Base-Case Analysis}

We calculated expected discounted lifetime costs and discounted QALYs, generated from the probabilistic sensitivity analysis (PSA) to account for the nonlinear feature of Markov models [60, 61], for each of the six strategies with the best estimates for all of the input parameters and preferred set of assumptions. Results were presented as incremental cost-effectiveness ratios (ICERs), measured as the additional cost per additional QALY gained. The most effective strategy with an ICER that is below the designated willingness-to-pay (WTP) threshold (i.e., the ratio of US\$100,000 per QALY suggested by Neumann et al. [62] in the US setting) would be declared as a cost-effective strategy. After the cost-effective strategy was decided, we further calculated its ICER in the 2.5th and 97.5th percentiles using the same PSA results mentioned above.

\subsubsection{Sensitivity Analysis}

We conducted deterministic sensitivity analyses and PSA to evaluate uncertainty with respect to all the parameters included in the simulation models. Table 1 presents the parameter values and their corresponding distributions. To ensure only meaningful scenarios, we required that the rank order of QALY weights in each PSA iteration was aligned with disease severity and residential settings [63], which implied that the health utility of $\mathrm{u}(\mathrm{MCI})>\mathrm{u}($ mild $\quad \mathrm{AD})>\mathrm{u}($ moderate $\quad \mathrm{AD})>\mathrm{u}($ severe AD) and $u($ community) $>\mathrm{u}$ (nursing home), applying the preference-ordering algorithm developed by GoldhaberFiebert and Jalal [64]. We presented PSA results using the cost-effectiveness acceptability curve (CEAC) [65], and further plotted the cost-effectiveness acceptability frontier (CEAF) [66, 67] on the top of CEAC to simultaneously present the optimal strategy and the level of uncertainty associated with that strategy at different WTP thresholds.

\subsubsection{Scenario Analysis}

We conducted the scenario analysis, assuming patients are allowed to receive treatment in the AD stage even if they were treated in the MCI stage, because this is the standard of care, even though the effectiveness of MCI treatment is unclear. Because it is not known whether treatment effectiveness for $\mathrm{AD}$ is the same for treated and untreated MCI patients, we further examined diminished treatment effectiveness in the AD stage for treated MCI patients. For untreated MCI patients, the treatment effectiveness in the AD stage was held constant at the base-case value (RR $0.58)$.

All analyses were performed in TreeAge Pro 2016 (TreeAge Software, INC, Williamstown, MA, USA), and Microsoft Excel (Microsoft Corp., Redmond, WA, USA). 


\section{Results}

\subsection{Base-Case Analysis}

Table 2 shows discounted costs and discounted QALYs for each strategy (the disaggregated total costs and QALYs by health states for each strategy is presented in Appendix A and B, respectively. In addition, we summarized the costs of medication, office visits, and CSF biomarker testing separated from total costs by disease stages and settings in Appendix $\mathrm{C}$, see electronic supplementary material $[\mathrm{ESM}])$. The most effective and most costly strategy was to test and treat MCI patients at low risk, which resulted in an ICER of US $\$ 37,700$ per QALY compared with not testing and not treating any MCI patient. The ICERs for this strategy at the 2.5th and 97.5th percentiles were US\$18,900 and US\$50,100 per QALY, respectively. In addition, results indicated that testing and treating patients at low risk was still the most cost-effective strategy with an ICER of US\$59,800 per QALY from a healthcare sector perspective (see Appendix D and $\mathrm{E}$ for disaggregated costs results in the ESM).

\subsection{Deterministic Sensitivity Analysis}

Table 3 summarizes the selected one-way sensitivity analysis results with ICERs and corresponding comparators for the key parameters (see Appendix F in the ESM for results with the remaining parameters). Our base-case results were most sensitive to variations in the effectiveness of treatment. For example, if the treatment effectiveness for mild $\mathrm{AD}$ patients was better than our base-case estimate, or the treatment effectiveness for MCI patients was worse than our base-case estimate, then no testing and no MCI treatment would be cost-effective. Our results were also sensitive to the health utility assigned to patients in the MCI stage. The cost of medication (donepezil) had little impact on our base-case results.

\subsection{Probabilistic Sensitivity Analysis}

Figure 2 shows the CEAC and the CEAF generated from our PSA. With the maximized expected outcomes shown in the base-case analysis, the strategy of testing and treating MCI patients at low risk showed a $26 \%$ probability of being costeffective at a WTP of US $\$ 100,000$ per QALY, whereas it was $30 \%$ for no testing and no MCI treatment. Testing and treating MCI patients at low risk was the strategy with the highest probability of being cost effective (29\%) for a WTP of US $\$ 150,000$ per QALY. Strategies of testing and treating high risk, and testing and treating high or intermediate risk showed a lower likelihood of cost-effectiveness compared with other test-and-treat strategies. They were less likely to be costeffective when WTP was higher than US $\$ 30,000$ per QALY.

\subsection{Scenario Analysis}

As expected, QALYs increased with the increasing number of treated MCI patients and the strategy of no testing and treating all MCI patients was associated with the highest cost and highest QALYs, with an ICER of US\$27,600 per QALY, given the relaxed assumption that patients are allowed to receive treatment in the $\mathrm{AD}$ stage even if they were treated in the MCI stage. All of the testing strategies were either strongly or weakly dominated. In addition, results of examining the diminished $\mathrm{AD}$ treatment effectiveness for treated MCI patients and a constant $\mathrm{AD}$ effectiveness for untreated $\mathrm{MCI}$ patients indicated that the strategy of no testing and treating all MCI patients remained the best strategy when the RR of the treatment effectiveness for AD was not worse than 0.65 at a WTP threshold of US $\$ 100,000$ per QALY (not shown).

\section{Discussion}

In this study, we sought to evaluate the potential value of using CSF biomarkers to target treatments, based on the best available data, for a subset of MCI patients according
Table 2 Base-case results (per patient) of performing CSF biomarker testing and subsequently treating MCI patients based on their risk levels of progression to $\mathrm{AD}$

\begin{tabular}{llll}
\hline Strategy & Cost (US\$) & QALYs & ICER (US\$/QALY) \\
\hline Test and treat high or intermediate risk & 270,593 & 7.471 & \\
Test and treat high risk & 270,735 & 7.475 & Weakly dominated \\
No testing and treat all MCI patients & 271,083 & 7.509 & 12,800 \\
No testing and no MCI treatment & 275,302 & 7.627 & Weakly dominated \\
Test and treat low or intermediate risk & 276,286 & 7.647 & Weakly dominated \\
Test and treat low risk & 276,428 & 7.651 & 37,700 \\
\hline
\end{tabular}

If patients received treatment in the MCI stage, no treatment would be provided when they convert to AD $A D$ Alzheimer's disease, CSF cerebrospinal fluid, ICER incremental cost-effectiveness ratio, $M C I$ mild cognitive impairment, $Q A L Y S$ quality-adjusted life-years

a The value was rounded to the nearest $\$ 100$. A weakly dominated strategy is a strategy with a higher ICER than a more costly strategy 
Table 3 Incremental cost-effectiveness ratios of one-way sensitivity analysis results with key parameters

\begin{tabular}{|c|c|c|c|c|c|c|}
\hline \multirow[t]{2}{*}{ Analysis $^{\mathrm{a}}$} & \multicolumn{6}{|c|}{ Test-and-treat strategy } \\
\hline & $\begin{array}{l}\text { Test and } \\
\text { treat low } \\
\text { risk }\end{array}$ & $\begin{array}{l}\text { Test and treat } \\
\text { low or } \\
\text { intermediate } \\
\text { risk }\end{array}$ & $\begin{array}{l}\text { No test and } \\
\text { no MCI } \\
\text { treatment }\end{array}$ & $\begin{array}{l}\text { No test } \\
\text { and treat } \\
\text { all MCI }\end{array}$ & $\begin{array}{l}\text { Test and } \\
\text { reat high } \\
\text { risk }\end{array}$ & $\begin{array}{l}\text { Test and treat } \\
\text { high or } \\
\text { intermediate } \\
\text { risk }\end{array}$ \\
\hline Base-case & $37,700^{\mathrm{b}}$ & Weakly DOM & Weakly DOM & $12,800^{\mathrm{c}}$ & Weakly DOM & - \\
\hline \multicolumn{7}{|c|}{ Annual probability of progression from MCI to $\mathrm{AD}$} \\
\hline At low risk, $1 \%$ & $38,500^{\mathrm{b}}$ & Weakly DOM & Weakly DOM & $19,000^{c}$ & Weakly DOM & - \\
\hline At low risk, $16 \%$ & Weakly DOM & Weakly DOM & $35,600^{\mathrm{b}}$ & - & Weakly DOM & Weakly DOM \\
\hline At intermediate risk, $3 \%$ & Weakly DOM & $40,700^{\mathrm{b}}$ & Weakly DOM & $20,400^{\mathrm{c}}$ & - & Weakly DOM \\
\hline At intermediate risk, $22 \%$ & $38,100^{\mathrm{b}}$ & Weakly DOM & Weakly DOM & $9400^{c}$ & Weakly DOM & - \\
\hline At high risk, $17 \%$ & $64,400^{\mathrm{d}}$ & Weakly DOM & $36,200^{\mathrm{b}}$ & $9500^{c}$ & Strongly DOM & - \\
\hline At high risk, $33 \%$ & $64,400^{\mathrm{d}}$ & Weakly DOM & $38,000^{\mathrm{b}}$ & $9500^{c}$ & Strongly DOM & - \\
\hline \multicolumn{7}{|l|}{ Treatment effectiveness (RR) } \\
\hline Mild AD, 0.35 & Strongly DOM & Strongly DOM & $16,400^{\mathrm{e}}$ & $\begin{array}{c}\text { Strongly } \\
\text { DOM }\end{array}$ & $7500^{\mathrm{c}}$ & - \\
\hline Mild AD, 0.76 & Strongly DOM & $438,000^{\mathrm{b}}$ & $\begin{array}{c}\text { Strongly } \\
\text { DOM }\end{array}$ & $5800^{c}$ & Strongly DOM & - \\
\hline Moderate AD, 0.64 & $199,000^{\mathrm{d}}$ & Strongly DOM & $27,800^{\mathrm{b}}$ & $8800^{c}$ & Weakly DOM & - \\
\hline Moderate AD, 1.41 & $64,400^{\mathrm{d}}$ & Weakly DOM & $37,300^{\mathrm{b}}$ & $9500^{c}$ & Strongly DOM & - \\
\hline MCI patients, 0.70 & Strongly DOM & $131,800^{\mathrm{b}}$ & $\begin{array}{c}\text { Strongly } \\
\text { DOM }\end{array}$ & - & Strongly DOM & Strongly DOM \\
\hline MCI patients, 1.02 & Strongly DOM & Strongly DOM & $10,300^{\mathrm{e}}$ & $\begin{array}{c}\text { Strongly } \\
\text { DOM }\end{array}$ & - & Strongly DOM \\
\hline \multicolumn{7}{|l|}{ Treatment harm } \\
\hline Annual prob. of AE (control), $20 \%$ & $75,300^{\mathrm{d}}$ & Strongly DOM & $34,400^{\mathrm{b}}$ & $9300^{c}$ & Strongly DOM & - \\
\hline Annual prob. of AE (control), $26 \%$ & $65,200^{\mathrm{d}}$ & Weakly DOM & $36,600^{\mathrm{b}}$ & $9600^{c}$ & Strongly DOM & - \\
\hline AEs in MCI (RR), 1.02 & $69,600^{\mathrm{d}}$ & Weakly DOM & $37,500^{\mathrm{b}}$ & $8600^{c}$ & Strongly DOM & - \\
\hline AEs in MCI (RR), 1.16 & $64,700^{\mathrm{d}}$ & Weakly DOM & $33,300^{\mathrm{b}}$ & $10,200^{c}$ & Strongly DOM & - \\
\hline AEs in $\mathrm{AD}(\mathrm{RR}), 1.81$ & $79,200^{\mathrm{d}}$ & Strongly DOM & $33,400^{\mathrm{b}}$ & $9400^{c}$ & Strongly DOM & - \\
\hline AEs in $\mathrm{AD}$ (RR), 2.40 & Strongly DOM & Strongly DOM & $10,200^{\mathrm{b}}$ & $\begin{array}{c}\text { Strongly } \\
\text { DOM }\end{array}$ & - & Strongly DOM \\
\hline Withdrawal due to $\mathrm{AE}, 13 \%$ & $78,700^{\mathrm{d}}$ & Strongly DOM & $44,500^{\mathrm{b}}$ & $7500^{c}$ & Strongly DOM & - \\
\hline Withdrawal due to AE, $22 \%$ & $64,800^{\mathrm{d}}$ & Weakly DOM & $35,600^{\mathrm{b}}$ & $10,700^{\mathrm{c}}$ & Weakly DOM & - \\
\hline \multicolumn{7}{|l|}{ Health utility } \\
\hline MCI patients, 0.58 & $995,200^{\mathrm{d}}$ & Strongly DOM & $26,500^{\mathrm{e}}$ & Weakly DOM & $15,400^{\mathrm{c}}$ & - \\
\hline MCI patients, 0.88 & Strongly DOM & $52,800^{\mathrm{b}}$ & Weakly DOM & $6200^{c}$ & Strongly DOM & - \\
\hline \multicolumn{7}{|l|}{ Health utility } \\
\hline AE, 0.916 & $53,500^{\mathrm{f}}$ & $53,000^{\mathrm{d}}$ & $44,900^{\mathrm{b}}$ & $8600^{c}$ & Strongly DOM & - \\
\hline AE, 0.976 & $84,900^{\mathrm{d}}$ & Strongly DOM & $31,700^{\mathrm{b}}$ & $10,300^{\mathrm{c}}$ & Strongly DOM & - \\
\hline Lumbar puncture, 0.009 & $78,600^{\mathrm{d}}$ & Strongly DOM & $35,500^{\mathrm{b}}$ & $9000^{c}$ & Strongly DOM & - \\
\hline Lumbar puncture, 0.012 & $61,300^{\mathrm{d}}$ & Weakly DOM & $37,300^{\mathrm{b}}$ & $9700^{c}$ & Strongly DOM & - \\
\hline \multicolumn{7}{|l|}{ Annual costs } \\
\hline MCI, US $\$ 3733$ & $72,100^{\mathrm{d}}$ & Strongly DOM & $35,500^{\mathrm{b}}$ & $8600^{c}$ & Strongly DOM & - \\
\hline MCI, US $\$ 11,200$ & $67,800^{\mathrm{d}}$ & Weakly DOM & $35,500^{\mathrm{b}}$ & $10,200^{c}$ & Strongly DOM & - \\
\hline \multicolumn{7}{|c|}{ Formal costs for patients dwelling in the community } \\
\hline Mild AD, US\$4690 & $96,600^{\mathrm{d}}$ & Strongly DOM & $14,300^{\mathrm{e}}$ & Weakly DOM & - & Strongly DOM \\
\hline Mild AD, US\$14,070 & $95,400^{\mathrm{f}}$ & $60,400^{\mathrm{b}}$ & $\begin{array}{c}\text { Strongly } \\
\text { DOM }\end{array}$ & - & Strongly DOM & Strongly DOM \\
\hline Moderate AD, US\$6929 & $59,100^{\mathrm{d}}$ & Weakly DOM & $42,100^{\mathrm{b}}$ & $4400^{c}$ & Strongly DOM & - \\
\hline Moderate AD, US\$20,788 & $80,400^{\mathrm{d}}$ & Weakly DOM & $28,900^{\mathrm{b}}$ & $14,500^{\mathrm{c}}$ & Weakly DOM & - \\
\hline
\end{tabular}


Table 3 continued

\begin{tabular}{|c|c|c|c|c|c|c|}
\hline \multirow[t]{2}{*}{ Analysis $^{\mathrm{a}}$} & \multicolumn{6}{|c|}{ Test-and-treat strategy } \\
\hline & $\begin{array}{l}\text { Test and } \\
\text { treat low } \\
\text { risk }\end{array}$ & $\begin{array}{l}\text { Test and treat } \\
\text { low or } \\
\text { intermediate } \\
\text { risk }\end{array}$ & $\begin{array}{l}\text { No test and } \\
\text { no MCI } \\
\text { treatment }\end{array}$ & $\begin{array}{l}\text { No test } \\
\text { and treat } \\
\text { all MCI }\end{array}$ & $\begin{array}{l}\text { Test and } \\
\text { reat high } \\
\text { risk }\end{array}$ & $\begin{array}{l}\text { Test and treat } \\
\text { high or } \\
\text { intermediate } \\
\text { risk }\end{array}$ \\
\hline Severe AD, US\$10,445 & $53,900^{\mathrm{f}}$ & $47,000^{\mathrm{b}}$ & Weakly DOM & $1300^{\mathrm{c}}$ & Strongly DOM & - \\
\hline Severe AD, US $\$ 31,334$ & $78,600^{\mathrm{d}}$ & Weakly DOM & $36,100^{\mathrm{b}}$ & $21,500^{\mathrm{e}}$ & $7400^{\mathrm{c}}$ & - \\
\hline \multicolumn{7}{|c|}{ Formal costs for patients dwelling in a nursing home } \\
\hline Mild AD, US\$25,432 & $75,900^{\mathrm{d}}$ & Weakly DOM & $26,800^{\mathrm{b}}$ & $17,600^{\mathrm{e}}$ & $10,700^{\mathrm{c}}$ & - \\
\hline Mild AD, US\$76,297 & $57,000^{\mathrm{d}}$ & Weakly DOM & $45,300^{\mathrm{b}}$ & $3400^{\mathrm{c}}$ & Strongly DOM & - \\
\hline Moderate AD, US\$27,681 & $62,800^{\mathrm{d}}$ & Weakly DOM & $38,200^{\mathrm{b}}$ & $8700^{c}$ & Strongly DOM & - \\
\hline Moderate AD, US\$83,043 & $70,800^{\mathrm{d}}$ & Weakly DOM & $35,200^{\mathrm{b}}$ & $9900^{\mathrm{c}}$ & Strongly DOM & - \\
\hline Severe AD, US $\$ 29,664$ & $62,500^{f}$ & $49,700^{\mathrm{b}}$ & Weakly DOM & $1600^{c}$ & Strongly DOM & - \\
\hline Severe AD, US\$88,991 & $88,700^{\mathrm{d}}$ & Weakly DOM & $22,700^{\mathrm{e}}$ & Weakly DOM & $2400^{\mathrm{c}}$ & - \\
\hline \multicolumn{7}{|c|}{ Excess mortality in moderate AD } \\
\hline Multiplier, $10 \%$ & $74,700^{\mathrm{d}}$ & Weakly DOM & $26,200^{\mathrm{b}}$ & $20,800^{\mathrm{e}}$ & $6200^{\mathrm{c}}$ & - \\
\hline Multiplier, $90 \%$ & $57,800^{\mathrm{d}}$ & Strongly DOM & $44,600^{\mathrm{b}}$ & $2200^{c}$ & Strongly DOM & - \\
\hline
\end{tabular}

The comparator strategy for the calculation of ICERs was varied by the value of parameters tested

$A D$ Alzheimer's disease, $A E$ adverse event, $D O M$ dominated, ICERs incremental cost-effectiveness ratios, $M C I$ mild cognitive impairment, $R R$ relative risk

a The value was rounded to the nearest $\$ 100$. - indicated the reference strategy. A weakly dominated strategy is a strategy with a higher ICER than a more costly strategy, and a strongly dominated strategy is a strategy that is more costly but less effective

b Compared with no testing and treat all MCI patients

c Compared with test and treat high or intermediate risk

d Compared with no testing and no MCI treatment

e Compared with test and treat high risk

f Compared with test and treat low or intermediate risk

Fig. 2 Cost-effectiveness acceptability curve showing the probability that a strategy is cost-effective at various willingness-to-pay thresholds. Vertical lines represent the incremental cost-effectiveness ratio for strategies of 'no testing and treat all MCI patients' (US\$12,800/QALY), and 'test and treat low risk' (US\$37,700/ QALY). $C E A F$ costeffectiveness acceptability frontier, $M C I$ mild cognitive impairment, $Q A L Y s$ qualityadjusted life years

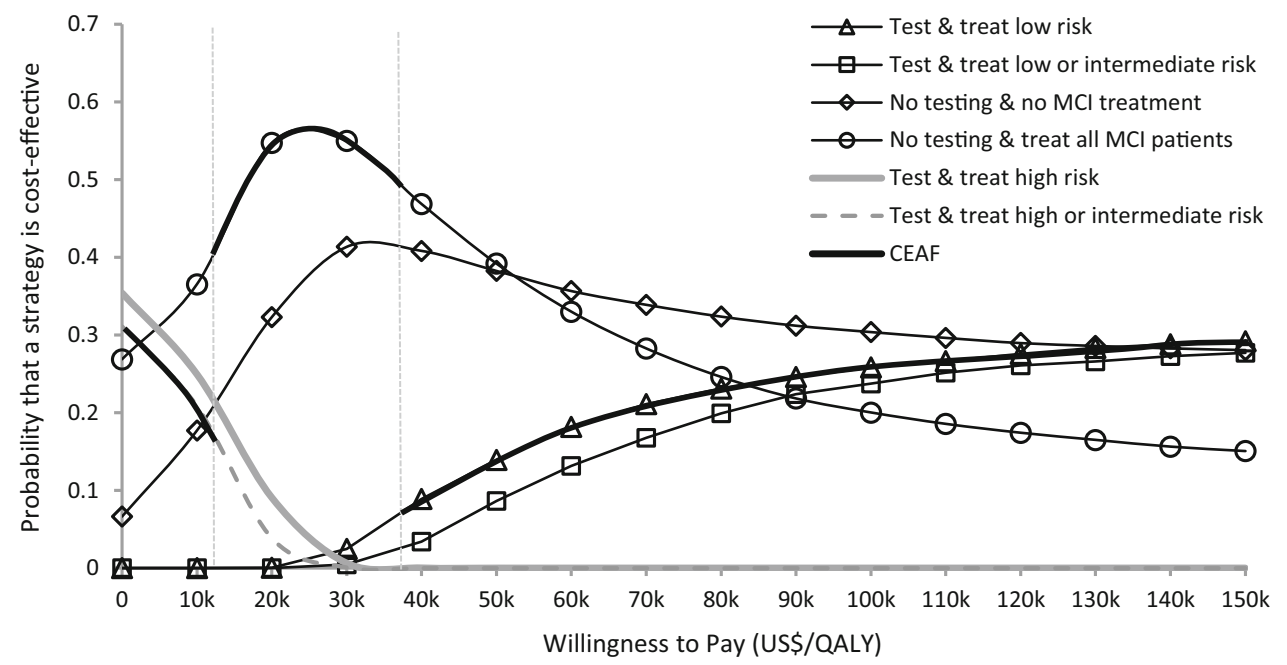

to their risk level of progression to AD. Our results indicated that testing and treating patients at low risk was costeffective with an ICER of US\$37,700 per QALY, which was more beneficial than treating patients at high risk, although such a practice would be contradictory to the widely held belief that interventions should usually be aimed at high-risk patients. However, the low-risk patients in our case were not comparable to the low-risk patients in the general population. They were instead low-risk patients among the MCI population-that is, referred to specialty 
clinics - and thus have a higher risk of progression to AD than the general population. Thus, the conventional rationale (targeting high-risk patients) might not be applicable in our case. Moreover, this finding may be associated with our assumption that treated MCI patients were ineligible for treatment if they converted to $\mathrm{AD}$, and that $\mathrm{MCI}$ patients at higher risk faced a relative short time until clinical diagnosis of $\mathrm{AD}$ in our model $[68,69]$. As a result, the trade-off between treatment effectiveness for MCI patients and for patients with mild AD was a key driver of this finding. With the more conservative assumption of treatment effectiveness for MCI patients utilized here when compared with other published models using a hypothetical DMT(RR 0.5) [29, 30, 70, 71], our finding may provide a more realistic picture of potential treatment effectiveness for MCI and AD patients.

Another possible explanation for the study finding is that treatment duration for MCI patients at high risk may be truncated (as we assumed the maximum treatment period was 3 years based on the available evidence) due to the conversion to AD. However, with results showing that time in MCI stage (without intervention) was 3.16, 6.48, and 8.67 years for patients at high, intermediate, or low risk, respectively, and a constant probability of transitioning from MCI to AD for high-risk patients was 0.244 annually, the treatment duration was less likely to be truncated at Year 3 for this group. It is also possible that the treatment response varied by MCI patients' CSF biomarker profiles (i.e., patients at high risk had a better response to the ChEI therapy than patients at intermediate or low risk). By assuming that MCI patients at high, intermediate, and low risk had $100 \%, 80 \%$, and $60 \%$ response to ChEI treatment, respectively, results of additional analyses indicated that no testing and no MCI treatment was cost-effective with an ICER of US\$30,000 per QALY, while it was US\$106,300 per QALY for treating patients at low risk (results not shown).

As indicated in the study by Sköldunger et al. [31], patients will live longer as a consequence of the treatment, and in turn accrue higher costs if providing treatment in the AD stage but not in the MCI stage. In our case, the strategy of 'no testing and no MCI treatment' reflected highest costs in the mild AD stage (due to the treatment costs and longer period in the mild AD stage, Appendix G, see ESM) but lowest costs in the moderate and severe AD stage. This may be explained by (1) a great difference between the treatment effectiveness for mild AD (RR 0.58) and moderate AD (RR 0.95), which implies that there is almost no treatment effect for moderate AD; (2) the time difference in the states (Appendix G, see ESM); and (3) age- and disease severity-related mortality rates. In this strategy, simulated patients were older when they progressed to moderate $\mathrm{AD}$ (6.285 QALYs in the MCI and mild AD stage), and thus with higher mortality rates, compared with the relatively younger population (6.023 QALYs in the MCI and mild AD stage) in the strategy of "no testing and treat all MCI patients'. Moreover, due to the modest treatment effectiveness for moderate AD, simulated patients with moderate $\mathrm{AD}$ either progressed to severe $\mathrm{AD}$ or death quickly. In addition, our findings are in line with the Sköldunger et al. study [31] oppositely with more time in the MCI stage and less time in the AD stage as a whole (the condensing effect) when treating MCI but not AD (no testing and treat all MCI patients).

It is of value to investigate the feasibility of the treatment continuum from MCI to AD stages. Not surprisingly, the scenario analysis where treatment was allowed in both MCI and AD stages produced greater benefits than when treatment was only allowed in one or the other. This implied that alternative interventions that allowed for the effectiveness to be carried over from MCI to AD stages would be considered as an optimal strategy. Furthermore, sensitivity analyses with a diminished AD treatment effectiveness for treated MCI patients and a constant effectiveness for untreated MCI patients indicated that no testing and treating of all MCI patients was cost-effective if the AD effectiveness for treated MCI patients was not worse than RR 0.65 .

Although previous studies concluded that CSF biomarker testing could allow one to identify MCI patients who are best suited for potential pharmacological treatment [19], this study suggests that treating low-risk MCI patients might lead to a greater benefit by slowing the progression to $\mathrm{AD}$. That is to say, clinicians or policy makers might consider the potential to intervene not only on higher-risk patients but on low-risk MCI patients when they initiate the disease management plan. Moreover, with the plausibility that MCI patients at high risk may be close to the threshold of $\mathrm{AD}$ diagnosis and that MCI patients in general are at a higher risk for progression than the general population, the findings again suggest that the MCI population might benefit greatly from early intervention with the use of CSF biomarker testing from a cost-effectiveness perspective. Further studies are needed to re-evaluate the benefits of early detection or diagnosis when the DMT is available.

It is possible that the most cost-effective (optimal) strategy may not have the highest probability of being costeffective [67]. In our case, the strategy of testing and treating patients at low risk was most cost-effective in the base-case analysis; however, its probability of being costeffective in the PSA was only $26 \%$ at a WTP of US\$100,000 per QALY. The results showed that there is a high degree of decision uncertainty surrounding the optimal strategy in the present study even with the best available evidence. In this case, the decision of whether to treat MCI patients or not may benefit from conducting 
value of information analysis to assess the potential gains to further research [72] such as gathering more information on the key parameters (i.e., the treatment effectiveness for MCI), before making a decision. However, there is a tradeoff between the potential gain for more research and the concurrent consequences (loss of potential benefits from early interventions) of not taking any action.

Our study has several limitations. Our modeling results were heavily subject to the inconclusive findings of treatment effectiveness. The treatment effectiveness of ChEIs for MCI patients was derived from a recent Cochrane review study [36] where authors reported evidence of minor benefits (effects for year 1 and year 3 were borderline significant; effects for year 2 were significant) with limitations and uncertainty, and further concluded that ChEI treatment is not recommended for MCI patients due to weak evidence. Compared with other similar studies using a hypothetical treatment effectiveness (RR 0.5) [29-31, 70, 71, 73], however, our assumption was relatively conservative (RR 0.84) and was based on point estimates reported from the most recent review evidence. Moreover, by applying the empirical data, our approach should better reflect what the real potential treatment benefits might be, acknowledge the debate of whether we should treat MCI patients or not based on the current evidence, and reflect that if a decision must be made, it should be made based on the available evidence [38].

No recent meta-analyses of treatment effectiveness for $\mathrm{AD}$ patients were presented as the measure of the RR, which was built-in in our model to reflect the treatmentassociated reduction on the risk of progression between the AD stages. Most studies [44, 74, 75] reported the effect size of this parameter as the point difference of cognitive tests, such as Mini-Mental State Examination (MMSE) or the AD and Associated Disorders Cognitive Scale between treatment and control arms instead of the risk reduction of transitions to more severe stages of $\mathrm{AD}$ (presented as the $\mathrm{RR}$ ). Hence, we applied the information from point differences of MMSE scores along with the proportion of patients with mild $\mathrm{AD}$ and moderate $\mathrm{AD}$ in an RCT to indirectly derive the RR of progression from the mild to moderate $\mathrm{AD}$ stage for the treatment group versus the control group.

The cost information [55] applied in this study is outdated due to the unavailability or inapplicability of recent data. Changes in many social and cultural factors are very likely to influence the cost estimates. However, we found that our base-case findings were robust under wide ranges of cost estimates examined in sensitivity analyses.

We were not able to account for the possible double treatment effects, which may lead to a potential bias of the study findings, resulting from the treatment effect embedded in the estimated transition probabilities derived from the scholarly literature where about $70 \%$ of their analysis sample were reported using $\mathrm{AD}$ medication. However, the cost-effectiveness metrics (ICERs) were the relative difference between the different test-and-treat strategies in terms of accrued costs and QALYs. In this case, the treatment effects should be compensated or minimal, which should not have major impact on our findings.

We acknowledge several limitations, such as solely using cognition as a driver of disease progression or a limited number of health states to present the natural history of disease due to the use of Markov modeling techniques [76, 77] existing in the current simulation models in AD. However, to build a model including indicators other than cognitive function would increase the complexity of the model structure, the trade-off between the complexity and transparency of a simulation model should be well balanced. The merit of using Markov models is that they provide a relatively transparent analysis and accessibility when compared with other models, such as discrete-event simulation models, which may induce overspecification where models may become more complex than necessary (as a result of computational challenges) to elicit accurate results [78].

We included a subset of all possible test-and-treat strategies in the CEA. Our rationale is that we attempted to find a threshold of CSF biomarker levels (a positive and ordinal association with risk levels of AD) that would decide which subset of MCI patients to treat from a costeffectiveness perspective. Therefore, it would not be logical to include strategies of 'treat MCI patients at intermediate risk only' or 'treat MCI patients at low or high risk' in the CEA due to the ordinal nature of the risk levels. Moreover, results of additional analyses including these two strategies indicated that they were both weakly dominated strategies.

For the transitions in the residential settings, we assumed once $\mathrm{AD}$ patients enter a nursing home they would remain in the institution until death. This may not reflect the current practice that patients transition among hospitals, home, and long-term care facilities within a short period of time. However, in our case, most of the patients who entered the nursing facility had severe AD. Accordingly, given the similar disease severity, the accumulative healthcare costs of staying in the nursing facility should be similar to the transitions among hospitals, home or longterm care facilities within the same periods of time from a social perspective.

We acknowledge that using CSF biomarkers only to categorize MCI patients into different risk levels of progression to AD may omit the potential added values from including other risk factors, such as patient demographics and their clinical characteristics. 


\section{Conclusion}

Based on the best available evidence regarding treatment effectiveness for MCI, this study suggests that performing CSF biomarker testing for early targeted treatments among MCI patients may be cost-effective. Interpretation of these results should be made with caution. Further research is needed to reduce the high degree of uncertainty regarding testing and treating MCI patients.

Author Contributions TLM and KMK: study design and analysis. All authors participated in the interpretation of data, drafting of manuscript, critical revision of manuscript, and approval of final manuscript.

\section{Compliance with Ethical Standards}

\section{Source of funding None.}

Conflict of interest TLM reports no conflicts of interest. RLK reports no conflicts of interest. JRM reports no conflicts of interest. JEG reports no conflicts of interest. JAN reports no conflicts of interest. KMK reports no conflicts of interest.

Data availability statement All data generated or analyzed during this study are included in this published article (and its electronic supplementary material files).

Open Access This article is distributed under the terms of the Creative Commons Attribution-NonCommercial 4.0 International License (http://creativecommons.org/licenses/by-nc/4.0/), which permits any noncommercial use, distribution, and reproduction in any medium, provided you give appropriate credit to the original author(s) and the source, provide a link to the Creative Commons license, and indicate if changes were made.

\section{References}

1. Alzheimer's Association. 2015 Alzheimer's disease facts and figures. Alzheimers Dement. 2015;11(3):332-84.

2. Brookmeyer R, Evans DA, Hebert L, Langa KM, Heeringa SG, Plassman BL, et al. National estimates of the prevalence of Alzheimer's disease in the United States. Alzheimers Dement. 2011;7(1):61-73.

3. Tarawneh R, Holtzman DM. Critical issues for successful immunotherapy in Alzheimer's disease: development of biomarkers and methods for early detection and intervention. CNS Neurol Disord Drug Targets. 2009;8(2):144-59.

4. Molinuevo JL, Blennow K, Dubois B, Engelborghs S, Lewczuk $\mathrm{P}$, Perret-Liaudet A, et al. The clinical use of cerebrospinal fluid biomarker testing for Alzheimer's disease diagnosis: a consensus paper from the Alzheimer's Biomarkers Standardization Initiative. Alzheimers Dement. 2014;10(6):808-17.

5. Petersen RC, Smith GE, Waring SC, Ivnik RJ, Tangalos EG, Kokmen E. Mild cognitive impairment: clinical characterization and outcome. Arch Neurol. 1999;56(3):303-8.

6. Farias ST, Mungas D, Reed BR, Harvey D, DeCarli C. Progression of mild cognitive impairment to dementia in clinic-vs community-based cohorts. Arch Neurol. 2009;66(9):1151-7.
7. Petersen RC. Mild cognitive impairment. NEJM. 2011;364(23):2227-34.

8. Bruscoli M, Lovestone S. Is MCI really just early dementia? A systematic review of conversion studies. Int Psychogeriatr. 2004;16(02):129-40.

9. Mattsson N, Zetterberg H, Hansson O, Andreasen N, Parnetti L, Jonsson M, et al. CSF biomarkers and incipient Alzheimer disease in patients with mild cognitive impairment. JAMA. 2009;302(4):385-93.

10. Petersen RC, Doody R, Kurz A, Mohs RC, Morris JC, Rabins PV, et al. Current concepts in mild cognitive impairment. Arch Neurol. 2001;58(12):1985-92.

11. Mattsson N, Brax D, Zetterberg H. To know or not to know: ethical issues related to early diagnosis of Alzheimer's disease. Int J Alzheimers Dis. 2010;2010:841941.

12. Holt GR. Timely diagnosis and disclosure of Alzheimer disease gives patients opportunities to make choices. South Med J. 2011;104(12):779-80.

13. Albert MS, DeKosky ST, Dickson D, Dubois B, Feldman HH, Fox NC, et al. The diagnosis of mild cognitive impairment due to Alzheimer's disease: recommendations from the National Institute on Aging-Alzheimer's Association workgroups on diagnostic guidelines for Alzheimer's disease. Alzheimers Dement. 2011;7(3):270-9.

14. Dubois B, Padovani A, Scheltens P, Rossi A, Dell'Agnello G. Timely diagnosis for Alzheimer's disease: a literature review on benefits and challenges. J Alzheimers Dis. 2016;49(3):617-31.

15. Hampel H, Frank R, Broich K, Teipel SJ, Katz RG, Hardy J, et al. Biomarkers for Alzheimer's disease: academic, industry and regulatory perspectives. Nat Rev Drug Discov. 2010;9(7):560-74.

16. Blennow $\mathrm{K}$, Zetterberg $\mathrm{H}$. The application of cerebrospinal fluid biomarkers in early diagnosis of Alzheimer disease. Med Clin North Am. 2013;97(3):369-76.

17. Shaw LM, Vanderstichele H, Knapik-Czajka M, Clark CM, Aisen PS, Petersen RC, et al. Cerebrospinal fluid biomarker signature in Alzheimer's disease neuroimaging initiative subjects. Ann Neurol. 2009;65(4):403-13.

18. van Rossum IA, Vos S, Handels R, Visser PJ. Biomarkers as predictors for conversion from mild cognitive impairment to Alzheimer-type dementia: implications for trial design. J Alzheimers Dis. 2010;20(3):881-91.

19. Michaud TL, Kane RL, McCarten JR, Gaugler JE, Nyman JA, Kuntz KM. Risk stratification using cerebrospinal fluid biomarkers in patients with mild cognitive impairment: an exploratory analysis. J Alzheimers Dis. 2015;47(3):729-40.

20. Lewczuk P. Currently available biomarkers and strategies for the validation of novel candidates for neurochemical dementia diagnostics in Alzheimer's disease and mild cognitive impairment. Adv Geriatr. 2014;2014.

21. Hampel H, Bürger K, Teipel SJ, Bokde AL, Zetterberg H, Blennow K. Core candidate neurochemical and imaging biomarkers of Alzheimer's disease. Alzheimers Dement. 2008;4(1):38-48.

22. Hampel H, Lista S, Teipel SJ, Garaci F, Nistico R, Blennow K, et al. Perspective on future role of biological markers in clinical therapy trials of Alzheimer's disease: a long-range point of view beyond 2020. Biochem Pharmacol. 2014;88(4):426-49.

23. Herukka S-K, Simonsen AH, Andreasen N, Baldeiras I, Bjerke $\mathrm{M}$, Blennow K, et al. Recommendations for CSF AD biomarkers in the diagnostic evaluation of MCI. Alzheimers Dement. 2017;13(3):274-84.

24. Dubois B, Feldman HH, Jacova C, Hampel H, Molinuevo JL, Blennow $\mathrm{K}$, et al. Advancing research diagnostic criteria for Alzheimer's disease: the IWG-2 criteria. Lancet Neurol. 2014;13(6):614-29. 
25. Guo S, Getsios D, Hernandez L, Cho K, Lawler E, Altincatal A, et al. Florbetaben PET in the early diagnosis of Alzheimer's disease: a discrete event simulation to explore its potential value and key data gaps. Int J Alzheimers Dis. 2012;2012.

26. Biasutti M, Dufour N, Ferroud C, Dab W, Temime L. Costeffectiveness of magnetic resonance imaging with a new contrast agent for the early diagnosis of Alzheimer's disease. PLoS One. 2012;7(4):e35559.

27. Djalalov S, Yong J, Beca J, Black S, Saposnik G, Musa Z, et al. Genetic testing in combination with preventive donepezil treatment for patients with amnestic mild cognitive impairment. Mol Diagn Ther. 2012;16(6):389-99.

28. Valcárcel-Nazco C, Perestelo-Pérez L, Molinuevo JL, Mar J, Castilla I, Serrano-Aguilar P. Cost-effectiveness of the use of biomarkers in cerebrospinal fluid for Alzheimer's disease. J Alzheimers Dis. 2014;42(3):777-88.

29. Handels RL, Joore MA, Tran-Duy A, Wimo A, Wolfs CA, Verhey FR, et al. Early cost-utility analysis of general and cerebrospinal fluid-specific Alzheimer's disease biomarkers for hypothetical disease-modifying treatment decision in mild cognitive impairment. Alzheimers Dement. 2015;11(8):896-905.

30. Barnett JH, Lewis L, Blackwell AD, Taylor M. Early intervention in Alzheimer's disease: a health economic study of the effects of diagnostic timing. BMC Neurol. 2014;14(1):101.

31. Sköldunger A, Johnell K, Winblad B, Wimo A. Mortality and treatment costs have a great impact on the cost-effectiveness of disease modifying treatment in Alzheimer's disease-a simulation study. Curr Alzheimer Res. 2013;10(2):207-16.

32. Petersen RC, Thomas RG, Grundman M, Bennett D, Doody R, Ferris S, et al. Vitamin E and donepezil for the treatment of mild cognitive impairment. NEJM. 2005;352(23):2379-88.

33. Diniz BS, Pinto JA Jr, Gonzaga MLC, Guimarães FM, Gattaz WF, Forlenza OV. To treat or not to treat? A meta-analysis of the use of cholinesterase inhibitors in mild cognitive impairment for delaying progression to Alzheimer's disease. Eur Arch Psychiatry Clin Neurosci. 2009;259(4):248-56.

34. Birks J, Flicker L. Donepezil for mild cognitive impairment. Cochrane Database Syst Rev. 2006;3.

35. Raschetti R, Albanese E, Vanacore N, Maggini M. Cholinesterase inhibitors in mild cognitive impairment: a systematic review of randomised trials. PLoS Med. 2007;4(11):e338.

36. Russ TC, Morling JR. Cholinesterase inhibitors for mild cognitive impairment. Cochrane Database Syst Rev. 2012;9.

37. Sobow T, Kloszewska I. Cholinesterase inhibitors in mild cognitive impairment: a meta-analysis of randomized controlled trials. Neurol Neurochir Pol. 2007;41(1):13-21.

38. Neumann PJ, Sanders GD, Russell LB, Siegel JE, Ganiats TG. Cost-effectiveness in health and medicine. Oxford: Oxford University Press; 2016.

39. Sanders GD, Neumann PJ, Basu A, Brock DW, Feeny D, Krahn $\mathrm{M}$, et al. Recommendations for conduct, methodological practices, and reporting of cost-effectiveness analyses: second panel on cost-effectiveness in health and medicine. JAMA. 2016:316(10):1093-103.

40. Spackman DE, Kadiyala S, Neumann PJ, Veenstra DL, Sullivan SD. Measuring Alzheimer disease progression with transition probabilities: estimates from NACC-UDS. Curr Alzheimer Res. 2012;9(9):1050-8.

41. Briggs AH, Weinstein MC, Fenwick EA, Karnon J, Sculpher MJ, Paltiel AD, et al. Model parameter estimation and uncertainty: a report of the ISPOR-SMDM Modeling Good Research Practices Task Force-6. Value Health. 2012;15(6):835-42.

42. Courtney C, Farrell D, Gray R, Hills R, Lynch L, Sellwood E, et al. Long-term donepezil treatment in 565 patients with Alzheimer's disease (AD2000): randomised double-blind trial. Lancet. 2004;363(9427):2105-15.
43. Amanzio M, Benedetti F, Vase L. A systematic review of adverse events in the placebo arm of donepezil trials: the role of cognitive impairment. Int Psychogeriatr. 2012;24(05):698-707.

44. Birks J. Cholinesterase inhibitors for Alzheimer's disease. Cochrane Rev. 2006:1.

45. Higgins JP, Green S. Cochrane handbook for systematic reviews of interventions. Hoboken: Wiley Online Library; 2008.

46. Peskind ER, Riekse R, Quinn JF, Kaye J, Clark CM, Farlow MR, et al. Safety and acceptability of the research lumbar puncture. Alzheimer Dis Assoc Disord. 2005;19(4):220-5.

47. Zetterberg H, Tullhög K, Hansson O, Minthon L, Londos E, Blennow K. Low incidence of post-lumbar puncture headache in 1,089 consecutive memory clinic patients. Eur Neurol. 2010;63(6):326-30.

48. Blennow K, Wallin A, Hager O. Low frequency of post-lumbar puncture headache in demented patients. Acta Neurol Scand. 1993;88(3):221-3.

49. Neumann PJ, Hermann RC, Kuntz KM, Araki SS, Duff SB, Leon J, et al. Cost-effectiveness of donepezil in the treatment of mild or moderate Alzheimer's disease. Neurology. 1999;52(6):1138-1145.

50. Neumann P, Hermann R, Weinstein M. Measuring QALYs in dementia. Health economics of dementia. New York: Wiley; 1998. p. $359-70$

51. Torrance GW, Feeny DH, Furlong WJ, Barr RD, Zhang Y, Wang Q. Multiattribute utility function for a comprehensive health status classification system: Health Utilities Index Mark 2. Med Care. 1996;34(7):702-22.

52. Ward MJ, Bonomo JB, Adeoye O, Raja AS, Pines JM. Costeffectiveness of diagnostic strategies for evaluation of suspected subarachnoid hemorrhage in the emergency department. Acad Emerg Med. 2012;19(10):1134-44.

53. Brookmeyer R, Johnson E, Ziegler-Graham K, Arrighi HM. Forecasting the global burden of Alzheimer's disease. Alzheimers Dement. 2007;3(3):186-91.

54. Johnson E, Brookmeyer R, Ziegler-Graham K. Modeling the effect of Alzheimer's disease on mortality. Int $\mathrm{J}$ Biostat. 2007;3(1).

55. Leon J, Cheng C-K, Neumann PJ. Alzheimer's disease care: costs and potential savings. Health Aff. 1998;17(6):206-16.

56. Leibson CL, Long KH, Ransom JE, Roberts RO, Hass SL, Duhig $\mathrm{AM}$, et al. Direct medical costs and source of cost differences across the spectrum of cognitive decline: a population-based study. Alzheimers Dement. 2015;11(8):917-32.

57. AccessPharmacy. http://accesspharmacy.mhmedical.com/drugs. aspx?gbosID=131908. Accessed 10 Oct 2014.

58. Doody R, Ferris S, Salloway S, Sun Y, Goldman R, Watkins W, et al. Donepezil treatment of patients with MCI A 48-week randomized, placebo-controlled trial. Neurology. 2009;72(18): 1555-61.

59. Bureau of Labor Statistics. Consumer price index-all urban consumers. https://data.bls.gov/pdq/SurveyOutputServlet. Accessed 18 July 2017.

60. Doubilet P, Begg CB, Weinstein MC, Braun P, McNeil BJ. Probabilistic sensitivity analysis using Monte Carlo simulation: a practical approach. Med Decis Making. 1984;5(2):157-77.

61. Koerkamp BG, Weinstein MC, Stijnen T, Heijenbrok-Kal MH, Hunink MM. Uncertainty and patient heterogeneity in medical decision models. Med Decis Making. 2010;30(2):194-205.

62. Neumann PJ, Cohen JT, Weinstein MC. Updating cost-effectiveness-the curious resilience of the \$50,000-per-QALY threshold. N Engl J Med. 2014;371(9):796-7.

63. Naveršnik K, Rojnik K. Handling input correlations in pharmacoeconomic models. Value Health. 2012;15(3):540-9.

64. Goldhaber-Fiebert JD, Jalal HJ. Some health states are better than others: using health state rank order to improve probabilistic analyses. Med Decis Making. 2015;36(8):927-40. 
65. Briggs AH, O'Brien BJ, Blackhouse G. Thinking outside the box: recent advances in the analysis and presentation of uncertainty in cost-effectiveness studies. Annu Rev Public Health. 2002;23(1):377-401.

66. Fenwick E, Claxton K, Sculpher M. Representing uncertainty: the role of cost-effectiveness acceptability curves. Health Econ. 2001;10(8):779-87.

67. Barton GR, Briggs AH, Fenwick EA. Optimal cost-effectiveness decisions: the role of the cost-effectiveness acceptability curve (CEAC), the cost-effectiveness acceptability frontier (CEAF), and the expected value of perfection information (EVPI). Value Health. 2008;11(5):886-97.

68. Aisen PS, Petersen RC, Donohue MC, Gamst A, Raman R, Thomas RG, et al. Clinical Core of the Alzheimer's disease neuroimaging initiative: progress and plans. Alzheimers Dement. 2010;6(3):239-46.

69. Vemuri P, Wiste H, Weigand S, Knopman D, Trojanowski J, Shaw L, et al. Serial MRI and CSF biomarkers in normal aging, MCI, and AD. Neurology. 2010;75(2):143-51.

70. Budd D, Burns LC, Guo Z, L'Italien G, Lapuerta P. Impact of early intervention and disease modification in patients with predementia Alzheimer's disease: a Markov model simulation. Clinicoecon Outcomes Res. 2011;3:189-95.

71. Knapp M, Comas-Herrera A, Wittenberg R, Hu B, King D, Rehill A, et al. Scenarios of dementia care: what are the impacts on cost and quality of life? Personal Social Services Research Unit, the London School of Economics and Political Science. London: 2014.

72. Oostenbrink JB, Al MJ, Oppe M, Rutten-van Mölken MP. Expected value of perfect information: an empirical example of reducing decision uncertainty by conducting additional research. Value Health. 2008;11(7):1070-80.
73. Furiak N, Klein R, Kahle-Wrobleski K, Siemers E, Sarpong E, Klein T. Modeling screening, prevention, and delaying of Alzheimer's disease: an early-stage decision analytic model. BMC Med Inform Decis Mak. 2010;10(1):24.

74. Di Santo SG, Prinelli F, Adorni F, Caltagirone C, Musicco M. A meta-analysis of the efficacy of donepezil, rivastigmine, galantamine, and memantine in relation to severity of Alzheimer's disease. J Alzheimers Dis. 2013;35(2):349-61.

75. Tan C-C, Yu J-T, Wang H-F, Tan M-S, Meng X-F, Wang C, et al. Efficacy and safety of donepezil, galantamine, rivastigmine, and memantine for the treatment of Alzheimer's disease: a systematic review and meta-analysis. J Alzheimers Dis. 2014;41(2):615-31.

76. Cohen JT, Neumann PJ. Decision analytic models for Alzheimer's disease: state of the art and future directions. Alzheimers Dement. 2008;4(3):212-22.

77. Green C, Shearer J, Ritchie CW, Zajicek JP. Model-based economic evaluation in Alzheimer's disease: a review of the methods available to model Alzheimer's disease progression. Value Health. 2011;14(5):621-30.

78. Standfield L, Comans T, Scuffham P. Markov modeling and discrete event simulation in health care: a systematic comparison. Int J Technol Assess Health Care. 2014;30(02):165-72.

79. Neumann P, Araki S, Arcelus A, Longo A, Papadopoulos G, Ka Kosik, et al. Measuring Alzheimer's disease progression with transition probabilities estimates from CERAD. Neurology. 2001;57(6):957-64.

80. Neumann PJ, Kuntz KM, Leon J, Araki SS, Hermann RC, Hsu M-A, et al. Health utilities in Alzheimer's disease: a cross-sectional study of patients and caregivers. Med Care. 1999;37(1):27-32. 